\title{
Relationship between Melatonin Rhythms and Visual Loss in the Blind*
}

\author{
STEVEN W. LOCKLEY, DEBRA J. SKENE, JOSEPHINE ARENDT, \\ HOMAYOUN TABANDEH, ALAN C. BIRD, AND REMY DEFRANCE \\ Chronobiology Laboratory, School of Biological Sciences, University of Surrey (S.W.L., D.J.S., J.A.), \\ Guildford; and the Institute of Ophthalmology, Moorfields Eye Hospital (H.T., A.C.B.), London, United \\ Kingdom; and Institut de Recherches Internationales Servier (R.D.), Courbevoie, France
}

\begin{abstract}
Melatonin rhythms were assessed in 49 registered blind individuals by measurement of the urinary metabolite of melatonin, 6-sulfatoxymelatonin (aMT6s). Subjects had different causes of visual loss and were classified as having light perception or better (LP; $n=19$ ) or having no perception of light (NPL; $n=30)$. Subjects collected four-hourly urine samples (eight-hourly overnight) for $48 \mathrm{~h}$ at weekly intervals for 3-5 weeks. The majority of LP subjects (14 of 19) had normally entrained aMT6s rhythms (mean acrophase range, 2.4-6.2 h), 4 were abnormally entrained to $24 \mathrm{~h}$ (mean acrophase range, 8.9-1.0 h), and 1 was unclassified. Conversely, most NPL subjects had abnormal rhythms (23 of 30$)$, the incidence of which was greater in
\end{abstract}

uni- and bilaterally enucleated subjects. The majority of NPL subjects (17 of 30 ) had free-running aMT6s rhythms (period range, 24.13$24.79 \mathrm{~h}$ ), 5 were abnormally entrained to $24 \mathrm{~h}$ (acrophase range, 7.2-20.6 h), and 1 was unclassified. Output (micrograms of aMT6s per $24 \mathrm{~h}$ ) and amplitude (micrograms per h) of aMT6s production did not vary between LP and NPL subjects (mean 24-h output \pm SD, $12.7 \pm$ 7.5 and $9.4 \pm 6.4 \mu \mathrm{g}$ aMT6s $/ 24 \mathrm{~h}$, respectively; mean amplitude $\pm \mathrm{SD}$, $0.6 \pm 0.4$ and $0.5 \pm 0.3 \mu \mathrm{g} / \mathrm{h}$, respectively). These results indicate that a higher proportion of NPL subjects have abnormal melatonin rhythms compared to those with LP. (J Clin Endocrinol Metab 82: 3763-3770, 1997)
$\mathrm{T}^{\mathrm{H}}$ HE PINEAL hormone melatonin is considered to be one of the most reliable markers of the periodicity of the endogenous body clock (1). Its production is highly rhythmic and is characterized by high nighttime levels and low daytime levels in normally entrained, sighted individuals. Its rhythm is highly reproducible in an individual, and unlike other circadian rhythms such as core body temperature or cortisol, it is minimally masked by sleep, activity, or stress (1-4). The major metabolite of melatonin is 6-sulfatoxymelatonin (aMT6s), and its pattern of production in both plasma and urine faithfully reflects that of melatonin in both normal (5-9) and phase-shifted conditions $(10,11)$. Abnormally timed melatonin production, as an indicator of circadian rhythm disorder, has been demonstrated in shift work (12, 13) and jet lag (14-16). The reduction of melatonin production and amplitude with increasing age $(17,18)$ is also associated with increased incidence of sleep disorder (19).

The circadian rhythm of melatonin is generated in the suprachiasmatic nuclei (SCN) of the hypothalamus, the site of the major circadian pacemaker, and it is entrained to the 24-h day primarily by the light-dark (LD) cycle (4). In the absence of a LD cycle (i.e. under constant conditions or temporal isolation), the melatonin rhythm reverts to its endogenous timing, usually to a "day" longer than $24 \mathrm{~h}(4,20)$. This

Received April 22, 1997. Revision received July 16, 1997. Accepted July 25, 1997.

Address all correspondence and requests for reprints to: Dr. Steven W. Lockley, Chronobiology Laboratory, School of Biological Sciences, University of Surrey, Guildford, Surrey, United Kingdom GU2 5XH. E-mail: s.lockley@surrey.ac.uk.

* This work was supported by the South Thames Regional Health Authority, United Kingdom; Stockgrand Ltd., University of Surrey, United Kingdom; and Servier Research and Development, France. light-dark control is mediated by the eyes and transduced to the SCN via the retinohypothalamic tract (RHT) (21). The periodicity and timing of circadian rhythms can thus be an indirect assessment of the integrity of the retina-RHT-SCN pathway.

Blind individuals may have abnormal retinal processing and/or a defective RHT and, therefore, may not be capable of photic entrainment. In this case, their circadian rhythms, including the rhythm of melatonin production, would be expected to exhibit a non-24-h pattern. The occurrence and incidence of free running rhythms in the blind have been documented for the rhythms of melatonin, temperature, cortisol, and, to a lesser extent, sleep (22-34). Studies have concluded that blind individuals can be classified into four categories: 1) normally entrained to $24 \mathrm{~h}, 2$ ) abnormally entrained to $24 \mathrm{~h}, 3$ ) free running with a period either greater or less than $24 \mathrm{~h}$, and 4) unstable, with no discernible pattern $(25,31)$.

In previous studies, the majority of blind individuals have had no conscious light perception. As the effects of light are intensity dependent with regard to both light-induced melatonin suppression $(7,35-37)$ and light-induced phase shifts in sighted humans $(38,39)$, the severity of visual loss may determine whether photic entrainment can occur. There has been no previous attempt to assess the relationship between endogenous circadian rhythms and visual loss or type of disease. Additionally, there have been few longitudinal field studies of blind individuals living in normal conditions measuring the effect of a conventional 24-h lifestyle on endogenous rhythms.

This report describes the aMT6s rhythms of 49 registered blind individuals, many of whom had sleep disorders, and 
relates the pattern of melatonin production to the severity of their visual loss and eye disease.

\section{Subjects and Methods}

\section{Subjects}

Forty-nine registered blind subjects were recruited from a database compiled to assess the incidence of sleep disorders in the blind (40). Ethical permission for the study was granted by the University of Surrey advisory committee on ethics and the Moorfields Eye Hospital ethics committee. Informed consent was obtained from all subjects and included consent for the assessment of urine for excluded medications. Ophthalmological examination and a structured interview revealed that they suffered from a range of diseases and that the duration and rapidity of onset of blindness varied (Table 1). Of these 49 individuals, 19 had conscious light perception or better (LP subjects), and 30 had no conscious perception of light (NPL subjects). LP subjects were classified according to the severity of their visual loss as having visual acuity of at least 3 / 60 vision $(n=7)$, being able to count fingers $(C F ; n=5)$, being able to see hand movements only $(\mathrm{HMO} ; \mathrm{n}=4)$, or being able to perceive light only (PL; $n=3$ ) and are referred to as LP subjects throughout this report (Table 1a). NPL subjects were classified into 3 groups according to the number of eyes present on the basis that there may be a quantitative difference in the number of photoreceptors present in each group [ 2 eyes present $(2 \mathrm{E} ; \mathrm{n}=12), 1$ eye present $(1 \mathrm{E} ; \mathrm{n}=7)$, or no eyes present $(0 \mathrm{E} ; \mathrm{n}=11)$; Table $1 \mathrm{~b}$

The majority of subjects ( $86 \%$ ) complained of a sleep disorder as assessed by the Pittsburgh Sleep Quality Index (PSQI; 25) (41). All of the subjects were in good health and were excluded if they were taking any medication known to affect sleep and/or melatonin production (tricyclic antidepressants, monoamine oxidase inhibitors, serotonin reuptake inhibitors, benzodiazepines, neuroleptics, $\beta$-blockers, or sleeping medication). During the study, 8 of 19 LP subjects and 21 of 30 NPL subjects were employed, with conventional working hours.

\section{Study schedule}

All subjects were studied for at least 3 consecutive weeks. No attempt was made to alter the lifestyles of the individuals during the study. For $48 \mathrm{~h}$ each week, the subjects collected sequential approximately fourhourly urine samples (eight-hourly overnight) for measurement of aMT6s. After each collection period, the subjects measured and recorded the volume or weight of the sample and the time of the urine collection period. A 5-mL urine aliquot was frozen $(-20 \mathrm{C})$ until assay of aMT6s.

\section{Assay}

Urinary aMT6s concentrations were measured by RIA using the method of Arendt et al. (5) adapted by Aldhous and Arendt (42). Antiserum was supplied by Stockgrand Ltd., University of Surrey (Guildford, UK; batch G/S/1118-23884). All samples from an individual were measured in a single assay. The intraassay coefficients of variation $(\mathrm{CVs})$ were $10.8 \%$ and $10.5 \%$ at $3.7 \mathrm{ng} / \mathrm{mL}(\mathrm{n}=10)$ and $26.4 \mathrm{ng} / \mathrm{mL}(\mathrm{n}=10)$ respectively, and the interassay coefficients of variation $(\mathrm{CV})$ were $17.7 \%, 21.8 \%, 12.8 \%$, and $10.0 \%$ at $3.4 \mathrm{ng} / \mathrm{mL}(\mathrm{n}=59), 23.5 \mathrm{ng} / \mathrm{mL}(\mathrm{n}=$ $59), 39.6 \mathrm{ng} / \mathrm{mL}(\mathrm{n}=32)$, and $43.9 \mathrm{ng} / \mathrm{mL}(\mathrm{n}=19)$, respectively.

\section{4-h aMT6s production}

The mean 24-h aMT6s output was calculated for each week (micrograms per $24 \mathrm{~h}$ ) for each subject with the associated CV. The data were grouped according to sex, age (19-29, 30-39, 40-49, 50-59, and $\geq 60 \mathrm{yr}$, severity of visual loss (LP subjects, $\geq 3 / 60$ vision, CF, HMO, PL; NPL subjects, two, one, or no eyes present), light perception (LP or NPL), and circadian rhythmicity (normally entrained, abnormally entrained, free running, and unclassified) and were assessed by one-way ANOVA.

\section{Assessment of circadian rhythmicity}

aMT6s output for each sequential collection period (nanograms per $\mathrm{mL}$ ) was converted to nanograms per $\mathrm{h}$ and subjected to cosinor analysis (software provided by Dr. D. S. Minors, University of Manchester, Manchester, UK) to provide the acrophase time $(\phi)$, amplitude, and mesor of the aMT6s rhythm. Only results that showed a significant fit to a cosine curve $(P<0.05)$ were used in further analyses. To assess any change in the timing of aMT6s production and to determine the periodicity of the rhythm for each subject, regression lines were fitted through the significant acrophases $(\tau=24 \mathrm{~h}+$ slope $)$. A rhythm was considered to be significantly free running when the $95 \%$ confidence limits of the line did not cross 0 (i.e. $24.00 \mathrm{~h}$ ). Subjects were considered to be entrained if the regression analysis was not significantly different from $24 \mathrm{~h}$. Subjects were classified as abnormally entrained if the mean acrophase time fell outside the normal range for sighted individuals (range; mean $\pm 2 \mathrm{sD}, 4.2 \pm 2.9 \mathrm{~h} ; \mathrm{n}=80$ ) (English J. and Arendt J., unpublished results) and as normally entrained if the mean acrophase

TABLE 1a. Details for 19 subjects with LP, categorized according to their severity of visual loss

\begin{tabular}{|c|c|c|c|c|c|c|}
\hline Subject no. & Sex & Age & $\begin{array}{l}\text { PSQI } \\
\text { score }\end{array}$ & Diagnosis & $\begin{array}{c}\text { Onset of } \\
\text { visual loss }\end{array}$ & $\begin{array}{c}\text { Rapidity } \\
\text { of loss }\end{array}$ \\
\hline \multicolumn{7}{|l|}{$\geq 3 / 60$ vision } \\
\hline 4 & $\mathrm{M}$ & 36 & 9 & Retinitis pigmentosa & 1988 & Years \\
\hline 5 & M & 52 & 8 & Retinitis pigmentosa & $1970 \mathrm{~s}$ & Years \\
\hline 8 & $\mathrm{M}$ & 23 & 8 & Fundus flavimaculatus & 1989 & Years \\
\hline 9 & $\mathrm{~F}$ & 46 & 12 & Acute zonal ocult outer retinopathy & 1991 & Days \\
\hline 10 & $\mathrm{M}$ & 24 & 13 & Retinitis pigmentosa & 1990 & Years \\
\hline 12 & $\mathrm{M}$ & 33 & 6 & Stargardt's disease & $1970 \mathrm{~s}$ & Years \\
\hline 47 & M & 61 & 7 & Congenital optic atrophy & Birth & \\
\hline \multicolumn{7}{|l|}{ Counting fingers } \\
\hline 1 & $\mathrm{~F}$ & 47 & 10 & Multifocal chorioretinitis, SRNVM, retinal detachment & 1991 & Weeks \\
\hline 2 & $\mathrm{~F}$ & 47 & 10 & SRNVM & 1993 & Days \\
\hline 11 & M & 35 & 7 & Retinitis pigmentosa & 1993 & Years \\
\hline 15 & $\mathrm{M}$ & 36 & 7 & Retinitis pigmentosa & 1980 & Years \\
\hline 19 & M & 26 & 6 & Retinitis pigmentosa & 1993 & Years \\
\hline \multicolumn{7}{|c|}{ Hand movements only } \\
\hline 3 & $\mathrm{~F}$ & 61 & 9 & Retinitis pigmentosa & 1973 & Years \\
\hline 7 & $\mathrm{M}$ & 59 & 9 & Retinitis pigmentosa & 1991 & Years \\
\hline 21 & $\mathrm{~F}$ & 35 & 6 & Retinal aplasia & Birth & \\
\hline \multirow{2}{*}{\multicolumn{7}{|c|}{ Perception of light only }} \\
\hline & & & & & & \\
\hline 6 & $\mathrm{M}$ & 41 & 8 & Retinopathy of prematurity & Birth & \\
\hline 40 & $\mathrm{~F}$ & 47 & 3 & Retinitis pigmentosa & 1958 & Years \\
\hline 41 & $\mathrm{M}$ & 35 & 6 & Retinal aplasia & Birth & \\
\hline
\end{tabular}

PSQI, Pittsburgh Sleep Quality Index (range, 0-21; a score $\geq 5$ is indicative of a sleep disorder); SRNVM, subretinalneovascular membrane. 
TABLE 1b. Details for 30 subjects with no NPL, categorized according to the number of eyes present

\begin{tabular}{|c|c|c|c|c|c|c|}
\hline Subject no. & Sex & $\begin{array}{l}\text { Age } \\
(\mathrm{yr})\end{array}$ & $\begin{array}{l}\text { PSQI } \\
\text { score }\end{array}$ & Diagnosis & $\begin{array}{c}\text { Onset of } \\
\text { visual loss }\end{array}$ & $\begin{array}{c}\text { Rapidity } \\
\text { of loss }\end{array}$ \\
\hline \multicolumn{7}{|l|}{2 eyes present } \\
\hline 13 & M & 48 & 12 & Retinal detachment, myopia & 1967 & Months \\
\hline 16 & $\mathrm{~F}$ & 61 & 6 & Retinal detachment & 1987 & Days \\
\hline 17 & M & 44 & 14 & Microphthalmia & 1965 & Years \\
\hline 22 & $\mathrm{~F}$ & 50 & 12 & Retinitis pigmentosa, retinal detachment, cataracts & 1985 & Years \\
\hline 25 & M & 62 & 11 & Retinitis pigmentosa, cataracts & $1960 \mathrm{~s}$ & Years \\
\hline 35 & $\mathrm{M}$ & 49 & 9 & Advanced diabetic retinopathy & 1972 & Days \\
\hline 38 & $\mathrm{M}$ & 57 & 7 & Retinal detachment & 1953 & Weeks \\
\hline 39 & $\mathrm{M}$ & 46 & 5 & Retinal detachment & 1993 & Days \\
\hline 42 & $\mathrm{~F}$ & 47 & 9 & Leber's congenital amaurosis & Birth & \\
\hline 46 & M & 36 & 3 & Retinal detachment & 1977 & Days \\
\hline 49 & M & 46 & 11 & Retinitis pigmentosa & 1965 & Years \\
\hline 50 & $\mathrm{~F}$ & 39 & 14 & Optic nerve injury & 1973 & Days \\
\hline \multicolumn{7}{|l|}{1 eye present } \\
\hline 14 & M & 32 & 11 & Measles keratitis & 1964 & Months \\
\hline 20 & M & 66 & 13 & Penetrating ocular trauma & 1945 & Days \\
\hline 26 & M & 44 & 5 & Buphthalmos, glaucoma & Birth & \\
\hline 27 & M & 72 & 4 & Penetrating ocular trauma & 1934 & Days \\
\hline 29 & M & 47 & 3 & Retinopathy of prematurity & Birth & \\
\hline 44 & $\mathrm{M}$ & 59 & 8 & Measles and penetrating ocular trauma & 1940 & Days \\
\hline 51 & $\mathrm{M}$ & 60 & 14 & Retinoblastoma & Birth & Years \\
\hline \multicolumn{7}{|c|}{ No eyes present } \\
\hline 18 & M & 44 & 16 & Retinopathy of prematurity, glaucoma & Birth & \\
\hline 23 & $\mathrm{M}$ & 41 & 8 & Retinoblastoma & 1955 & Months \\
\hline 24 & M & 68 & 12 & Retinal detachment & $1940 \mathrm{~s}$ & Weeks \\
\hline 28 & M & 65 & 7 & Leber's congenital amaurosis & 1938 & Months \\
\hline 31 & M & 35 & 3 & Retinoblastoma & 1965 & Years \\
\hline 33 & M & 55 & 4 & Penetrating ocular trauma & 1947 & Days \\
\hline 34 & $\mathrm{~F}$ & 19 & 5 & Anophthalmia & Birth & \\
\hline 36 & M & 44 & 3 & Behçet's syndrome & 1964 & Years \\
\hline 43 & M & 35 & 12 & Retinoblastoma & 1962 & Months \\
\hline 45 & $\mathrm{M}$ & 42 & 8 & Penetrating ocular trauma & 1986 & Days \\
\hline 48 & $\mathrm{~F}$ & 54 & 14 & Retinoblastoma & Birth & \\
\hline
\end{tabular}

PSQI, Pittsburgh Sleep Quality Index (range, 0-21; a score $\geq 5$ is indicative of a sleep disorder).

fell inside the normal range. For free running subjects, any correlations of $\tau$ with age and PSQI score were determined. Amplitudes derived from cosinor analysis were analyzed by one-way ANOVA to investigate any difference between subjects, and a CV for amplitude was calculated to measure within subject variability. The data were grouped according to sex, age, severity of visual loss, light perception, and circadian rhythmicity as described for 24-h aMT6s production and were assessed by one-way ANOVA.

\section{Age and PSQI}

\section{Results}

The mean age and PSQI scores ( \pm SD) for the whole population $(\mathrm{n}=49)$ were $46.1 \pm 12.3 \mathrm{yr}$ (range, $19-72 \mathrm{yr}$ ) and $8.4 \pm 3.5$ (range, 3-16), respectively. There were no significant differences with respect to age or PSQI score within the LP subgroups, within NPL subgroups, or between all LP and NPL subgroups (by one-way ANOVA, P>0.05; Fig. 1, A and B). Overall, however, NPL subjects were significantly older than LP subjects (mean ages \pm SD for LP and NPL subjects were $41.7 \pm 11.7$ and $48.9 \pm 12.0 \mathrm{yr}$, respectively; $P<0.05$ ), although there was no significant difference in the PSQI scores $(P>0.05$; Fig. $1, \mathrm{~A}$ and $\mathrm{B})$.

\section{4-h aMT6s production}

All subjects produced measurable amounts of urinary aMT6s. There was a high degree of consistency in the 24-h aMT6s output within an individual. The mean CVs ( \pm SD) for 24-h aMT6s output for LP and NPL subjects were $21.3 \pm$
$10.9 \%$ and $17.1 \pm 12.3 \%$, respectively. There was no significant difference in the mean 24-h output within LP or NPL subgroups, between all LP and NPL subgroups, or overall between LP and NPL subjects ( $P>0.05$; Fig. 1C). The mean $( \pm \mathrm{SD})$ 24-h aMT6s outputs were $12.7 \pm 7.5 \mu \mathrm{g} / 24 \mathrm{~h}$ (range, $1.9-28.6 \mu \mathrm{g} / 24 \mathrm{~h}$ ) and $9.4 \pm 6.4 \mu \mathrm{g} / 24 \mathrm{~h}$ (range, 1.7-30.1 $\mu \mathrm{g} / 24 \mathrm{~h}$ ) for LP and NPL subjects, respectively. There was no significant effect of age on aMT6s output $(P>0.05)$, but there was a trend for output to decrease with increasing age $(\mathrm{r}=-0.19)$. There was also no significant difference between the 24-h aMT6s output with respect to sex $(P>0.05)$.

\section{Assessment of circadian rhythmicity}

Subjects with light perception. Overall, 18 of the 19 LP subjects showed a significant rhythm in aMT6s production, as assessed by cosinor analysis. Table $2 \mathrm{~A}$ shows the mean acrophase times and the period of the aMT6s rhythm. With respect to the severity of visual loss, Table 3 shows that the majority of subjects in the LP subgroups were normally entrained (range, 57-100\%), and a minority of subjects were abnormally entrained (range, 20-33\%). One subject (S8) did not show any significant rhythm and was defined as unclassified. Overall, of the 19 LP subjects, 14 individuals had normally entrained aMT6s rhythms (74\%), 4 subjects appeared to be abnormally entrained $(21 \%)$, and 1 was unclassified (5\%; Table 3). Figure $2 \mathrm{~A}$ shows a representative example of a subject with a normally entrained aMT6s rhythm. 

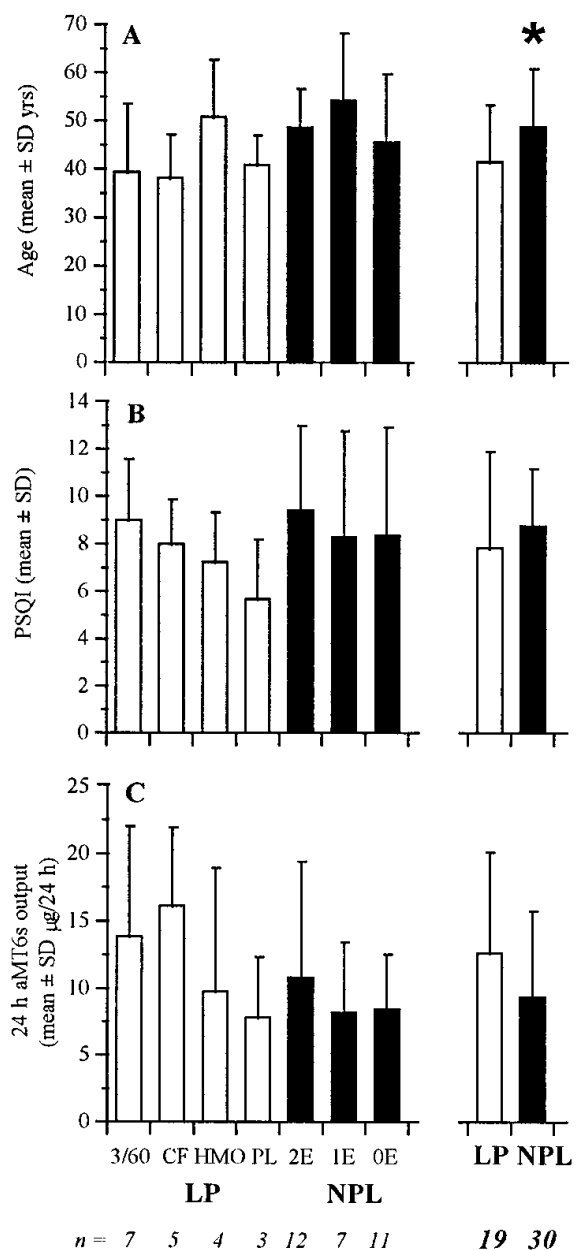

FIG. 1. The mean ( \pm SD) for age (A), PSQI (B), and 24-h aMT6s output for all subjects according to severity of visual loss (LP subjects) and the number of eyes present (NPL subjects). The white columns represent LP subgroups (3/60 vision or better; $\mathrm{CF}$, counting fingers; HMO, hand movements only; PL, light perception only), and the black columns represent NPL subgroups (2E, two eyes present; $1 \mathrm{E}$, one present; $0 \mathrm{E}$, no eyes present). The number (n) of subjects in each subgroup is shown. There were no significant differences between the subgroups for age, PSQI, or 24-h output, although there was an overall significant difference between the ages of LP and NPL subjects, represented by an asterisk (by one-way ANOVA, $P<0.05$ ).

Four LP individuals had less than three significant acrophases and were classified according to their significant acrophase results albeit with some reservation as to the confidence of the classification. S3 and S37 had single acrophase times within the normal range, whereas S40 and S47 had single acrophases outside the normal range. In cases like these it is not possible to determine whether a single acrophase, normal or abnormal, is part of a free running rhythm or an entrained rhythm. Observation of the raw data plots suggested they had relatively stable, and therefore entrained, rhythms [normally (S3, S37) or abnormally (S40, S47) entrained] rather than free running rhythms.

Subjects with no perception of light. Overall, 29 of 30 NPL subjects showed a significant rhythm in aMT6s production (Table 2B). With respect to the number of eyes present in NPL subjects, Table 3 and Fig. 3 show that the distribution of the circadian rhythm types varied among the 3 NPL subgroups. The incidence of rhythm abnormalities was greater in unilaterally and bilaterally enucleated individuals ( 2 eyes present, $42 \%$ abnormally entrained, $17 \%$ free-running; 1 eye present, $71 \%$ free-running; no eyes present, $91 \%$ freerunning; Table 3). One subject (S35) did not show any significant rhythm and was defined as unclassified. Three NPL subjects (S28, S43, and S46) had visibly free-running rhythms, but the $95 \%$ confidence limits of the line crossed $24.00 \mathrm{~h}$. An additional subject (S45) was classified as free running, although due to technical problems, there were fewer samples, and the cosinor fits were nonsignificant. Observation of the raw data plots revealed a free-running rhythm with a $\tau$ of approximately $24.9 \mathrm{~h}$

Overall, of the 30 NPL subjects, 7 individuals were normally entrained $(23 \%), 5$ subjects were abnormally entrained $(17 \%), 17$ subjects appeared to be free running $(57 \%)$, and 1 was unclassified (3\%; Table 3). Figure 2, B and C, shows representative plots of individuals with abnormally entrained and free running aMT6s rhythms, respectively.

In free-running NPL subjects, there was no significant correlation between $\tau$ and the age or PSQI score of the subjects $(r=-0.05$ and -0.14 , respectively). There was no significant difference in age, PSQI, or 24-h aMT6s output within all subjects $(n=49)$ when classified according to the four circadian types $(P>0.05)$. There was also no effect of rapidity or duration of blindness on circadian type.

There was a significant difference $(P<0.05)$ in the mean amplitude between individuals, although this was not associated with any particular variable. The mean $( \pm \mathrm{SD})$ amplitudes were $0.6 \pm 0.4 \mu \mathrm{g} / \mathrm{h}$ (range, $0.1-1.4 \mu \mathrm{g} / \mathrm{h}$ ) and $0.5 \pm$ $0.3 \mu \mathrm{g} / \mathrm{h}$ (range, $0.1-1.4 \mu \mathrm{g} / \mathrm{h}$ ) for LP and NPL subjects, respectively. However, aMT6s rhythm amplitudes were consistent within an individual; the mean CVs $( \pm \mathrm{SD})$ for amplitude for LP and NPL subjects were $23.6 \pm 9.7 \%$ and $27.9 \pm$ $22.9 \%$, respectively. There was no significant difference in the mean amplitude within and between LP and NPL subgroups $(P>0.05)$. Similarly, there was no significant difference in the mean amplitude between the different circadian rhythm types $(P>0.05)$. There was a nonsignificant trend for a decrease in amplitude with increasing age in all subjects $(\mathrm{r}=$ $-0.28)$.

\section{Disease}

Several diseases were prevalent in the study population. Only individuals with eyes were included in this assessment, as the loss of eyes clearly prevents analysis of light perception in relation to disease.

Ten of the 19 LP subjects and 4 of the 19 NPL subjects with eyes suffered from a form of retinitis pigmentosa (RP). Eleven of the RP subjects had normally entrained aMT6s rhythms (8 LP and 3 NPL), and 3 appeared to have abnormally entrained rhythms (2 LP and 1 NPL). Retinal detachment was present in $1 \mathrm{LP}$ subject and 6 of the 19 NPL subjects with intact eyes. Of these, 2 were normally entrained (1 LP and 1 NPL), 4 were abnormally entrained (4 NPL), and 1 subject had a free running aMT6s rhythm (1 NPL). No other diseases were common to more than 3 subjects. 
TABLE 2. Tables $2 \mathrm{~A}$ and $2 \mathrm{~B}$ show the mean acrophase times $( \pm \mathrm{SD})$ and period of the aMT6s rhythm ( $\pm 95 \%$ confidence limits) for all LP and NPL subjects, respectively, categorized by severity of visual loss and the number of eyes present; circadian rhythm type is also shown

\begin{tabular}{|c|c|c|c|}
\hline Subject No. & $\begin{array}{l}\text { Acrophase } \\
\text { mean }( \pm \mathrm{SD})\end{array}$ & $\begin{array}{l}\text { Period of aMT6s rhythm } \\
\quad( \pm 95 \% \text { limits })\end{array}$ & Circadian type \\
\hline \multicolumn{4}{|l|}{ Table 2A } \\
\hline \multicolumn{4}{|l|}{$\geq 3 / 60$ vision } \\
\hline 4 & $4.30(1.10)$ & 24.00 & Normally entrained \\
\hline 5 & $6.23(0.64)$ & 24.00 & Normally entrained \\
\hline 10 & $4.33(0.85)$ & 24.00 & Normally entrained \\
\hline 12 & $4.20(0.64)$ & 24.00 & Normally entrained \\
\hline 9 & $1.03(0.81)$ & 24.00 & Abnormally entrained \\
\hline 47 & 9.00 & & Abnormally entrained \\
\hline 8 & NS & & Unclassified \\
\hline \multicolumn{4}{|l|}{ Counting fingers } \\
\hline 1 & $4.48(1.08)$ & 24.00 & Normally entrained \\
\hline 2 & $3.07(1.21)$ & 24.00 & Normally entrained \\
\hline 19 & $5.03(0.74)$ & 24.00 & Normally entrained \\
\hline 11 & $2.43(1.46)$ & 24.00 & Normally entrained \\
\hline 15 & $8.90(0.90)$ & 24.00 & Abnormally entrained \\
\hline \multicolumn{4}{|c|}{ Hand movements only } \\
\hline 3 & 4.70 & & Normally entrained \\
\hline 7 & $4.90(1.92)$ & 24.00 & Normally entrained \\
\hline 21 & $4.28(0.21)$ & 24.00 & Normally entrained \\
\hline 37 & 4.10 & & Normally entrained \\
\hline \multicolumn{4}{|c|}{ Perception of light only } \\
\hline 6 & $4.80(0.99)$ & 24.00 & Normally entrained \\
\hline 41 & $4.30(0.70)$ & 24.00 & Normally entrained \\
\hline 40 & 21.20 & & Abnormally entrained \\
\hline \multicolumn{4}{|l|}{ Table 2B } \\
\hline \multicolumn{4}{|l|}{2 eyes present } \\
\hline 25 & $2.80(0.62)$ & 24.00 & Normally entrained \\
\hline 39 & $5.73(1.38)$ & 24.00 & Normally entrained \\
\hline 42 & $3.10(0.32)$ & 24.00 & Normally entrained \\
\hline 49 & $2.7(0.28)$ & & Normally entrained \\
\hline 13 & $14.25(1.08)$ & 24.00 & Abnormally entrained \\
\hline 16 & $20.30(0.62)$ & 24.00 & Abnormally entrained \\
\hline 22 & $20.57(0.06)$ & 24.00 & Abnormally entrained \\
\hline 38 & $7.88(0.59)$ & 24.00 & Abnormally entrained \\
\hline 50 & 7.20 & & Abnormally entrained \\
\hline 17 & $17.18(3.13)$ & $24.34(24.24-24.44)$ & Free running \\
\hline 46 & $23.73(3.59)$ & $24.54(23.16-25.92)$ & Free running \\
\hline 35 & NS & & Unclassified \\
\hline \multicolumn{4}{|l|}{1 eye present } \\
\hline 27 & $3.25(0.53)$ & 24.00 & Normally entrained \\
\hline 29 & $2.13(0.15)$ & 24.00 & Normally entrained \\
\hline 14 & $21.78(7.17)$ & $24.79(24.70-24.88)$ & Free running \\
\hline 20 & $3.74(7.57)$ & $24.68(24.48-24.87)$ & Free running \\
\hline 26 & $13.95(3.65)$ & $24.39(24.05-24.73)$ & Free running \\
\hline 44 & $13.18(3.30)$ & $24.35(24.04-24.66)$ & Free running \\
\hline 51 & $18.2(3.40)$ & $24.37(24.25-24.49)$ & Free running \\
\hline \multicolumn{4}{|l|}{0 eyes present } \\
\hline 34 & $6.65(1.17)$ & 24.00 & Normally entrained \\
\hline 18 & $17.05(8.15)$ & $24.68(24.47-24.89)$ & Free running \\
\hline 23 & $17.83(4.98)$ & $24.39(24.29-24.49)$ & Free running \\
\hline 24 & $11.53(5.57)$ & $24.59(24.05-25.10)$ & Free running \\
\hline 28 & $11.86(4.07)$ & $24.41(23.83-24.99)$ & Free running \\
\hline 31 & $5.98(6.23)$ & $24.68(24.43-24.93)$ & Free running \\
\hline 33 & $2.40(6.45)$ & $24.60(24.32-24.88)$ & Free running \\
\hline 36 & $10.25(5.37)$ & $24.60(24.32-24.88)$ & Free running \\
\hline 43 & $10.33(1.40)$ & $24.13(23.95-24.31)$ & Free running \\
\hline 45 & 2.10 & $>24.00$ & Free running \\
\hline 48 & $11.75(5.41)$ & $24.41(24.15-24.68)$ & Free running \\
\hline
\end{tabular}

NS, No significant acrophase times. 
TABLE 3. Summary of the circadian classification for all subjects according to severity of visual loss (LP subjects) and the number of eyes present (NPL subjects)

\begin{tabular}{|c|c|c|c|c|c|}
\hline \multirow[b]{2}{*}{ Severity of visual loss } & \multicolumn{4}{|c|}{ Circadian type } & \multirow[b]{2}{*}{ Total } \\
\hline & $\begin{array}{l}\text { Normally } \\
\text { entrained }\end{array}$ & $\begin{array}{c}\text { Abnormally } \\
\text { entrained }\end{array}$ & $\begin{array}{c}\text { Free } \\
\text { running }\end{array}$ & Unclassified & \\
\hline \multicolumn{6}{|l|}{$\overline{\mathrm{LP}}$} \\
\hline Counting fingers & $4(80)$ & $1(20)$ & 0 & 0 & 5 \\
\hline Hand movements & $4(100)$ & 0 & 0 & 0 & 4 \\
\hline Perception of light & $2(67)$ & $1(33)$ & 0 & 0 & 3 \\
\hline Subtotal & $14(\mathbf{7 4})$ & $4(\mathbf{2 1})$ & 0 & $1(5)$ & 19 \\
\hline 1 eye present & $2(29)$ & 0 & $5(71)$ & 0 & 7 \\
\hline 0 eyes present & $1(9)$ & 0 & $10(91)$ & 0 & 11 \\
\hline Subtotal & $7(\mathbf{2 3})$ & $5(\mathbf{1 7})$ & $17(\mathbf{5 7})$ & $1(\mathbf{3})$ & 30 \\
\hline Total & 21 & 9 & 17 & 2 & 49 \\
\hline
\end{tabular}

The circadian type is defined as normally entrained (NE), abnormally entrained (AE), free running (FR), and unclassified (UN) aMT6s rhythm. Figures in italic parentheses show the percent incidence of each circadian type within each subgroup, and figures in bold parentheses show the percent incidence in LP or NPL subjects overall.
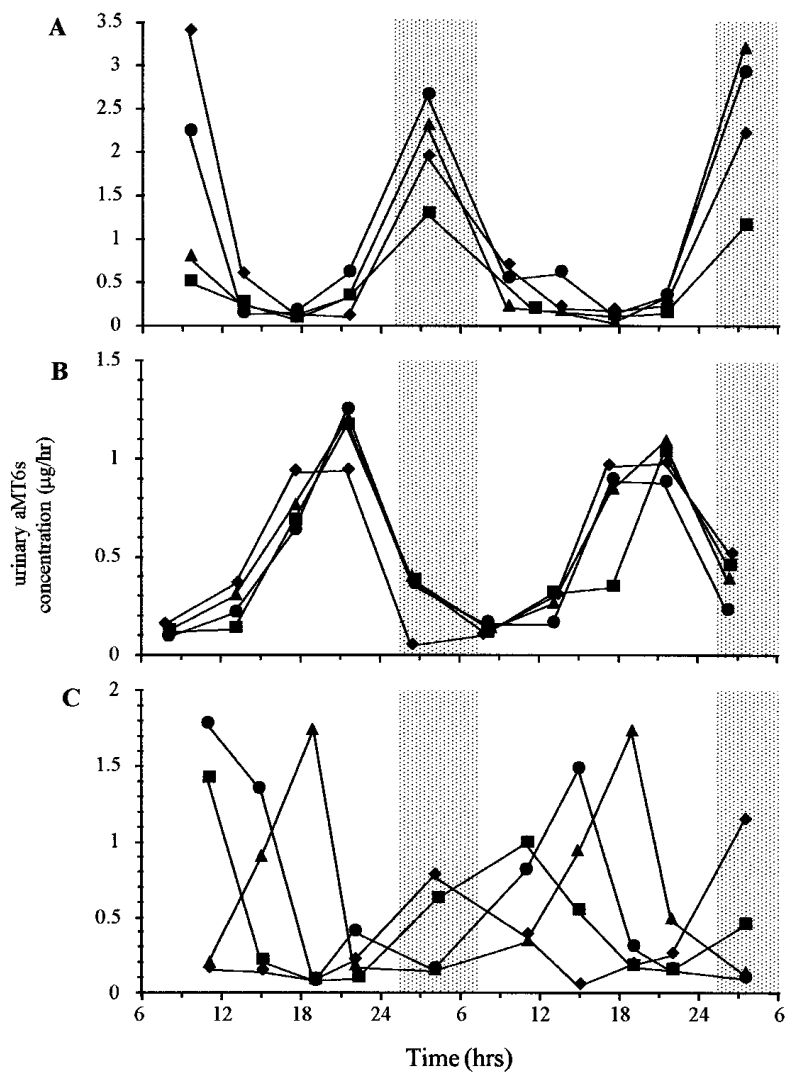

FIG. 2. Representative plots of weekly 48-h aMT6s profiles (micrograms per h) for a normally entrained (S1; A), an abnormally entrained (S16; B), and a free running (S18; C) subject. The shaded area represents the range over which aMT6s acrophase is considered normal $(\mathrm{n}=80)$ (English J. and Arendt J., unpublished results).

\section{Discussion}

The present findings show that a high proportion (77\%) of registered blind people with no perception of light (NPL) had abnormal circadian rhythms as assessed by the pattern of melatonin production. Within the NPL group, the incidence of circadian aMT6s abnormalities is greater in unilaterally and bilaterally enucleated individuals. Conversely, a much lower proportion of subjects with light perception or better (LP) have abnormal aMT6s rhythms (26\%), and it appears that within the LP groups, decreasing vision does not influence the incidence of abnormal rhythms.

As the phase-shifting effects of light are intensity dependent $(38,39)$, it is possible that the rhythm abnormalities found were due to insufficient light intensities in the subjects' normal environment. The light intensities to which these individuals were exposed were not measured in this study, but they were all living in a normal environment and were exposed to light intensities comparable to those experienced by sighted individuals who are known to exhibit normally entrained rhythms in these lighting conditions. Therefore, it is unlikely that the abnormal aMT6s rhythms observed are due to insufficient light exposure.

Blind subjects with normally entrained rhythms are likely to have an intact and functional RHT, whereas in subjects with free running rhythms, the RHT is likely to be dysfunctional. The type and anatomical position of the disease and/or the number of eyes present may quantitatively alter the number of "circadian" photoreceptors of the retina. Of the NPL subjects, those with one or two eyes present have the highest proportion of individuals who are normally entrained, and this may be due to light entraining the SCN via an intact retina-RHT-SCN pathway $(31,32)$. The finding that some individuals with one eye present have normally entrained rhythms supports the idea that bilateral photic innervation is not required for subconscious circadian entrainment.

Subjects with no eyes by definition do not have an intact retina-RHT-SCN pathway and, therefore, would not be expected to have photically entrained rhythms. This hypothesis is upheld in the present results. Only one subject (S34) did not appear to have a free running rhythm. Although this subject has been diagnosed as anophthalmic (i.e. the eyes are not present), there is the possibility that this subject may have vestigial eyes remaining (cryptophthalmos), and that subconscious light perception is entraining the rhythm. There are two other possible hypotheses to explain this finding. A likely explanation is that our 4-week study was not long enough to detect individuals with a slow, free running 

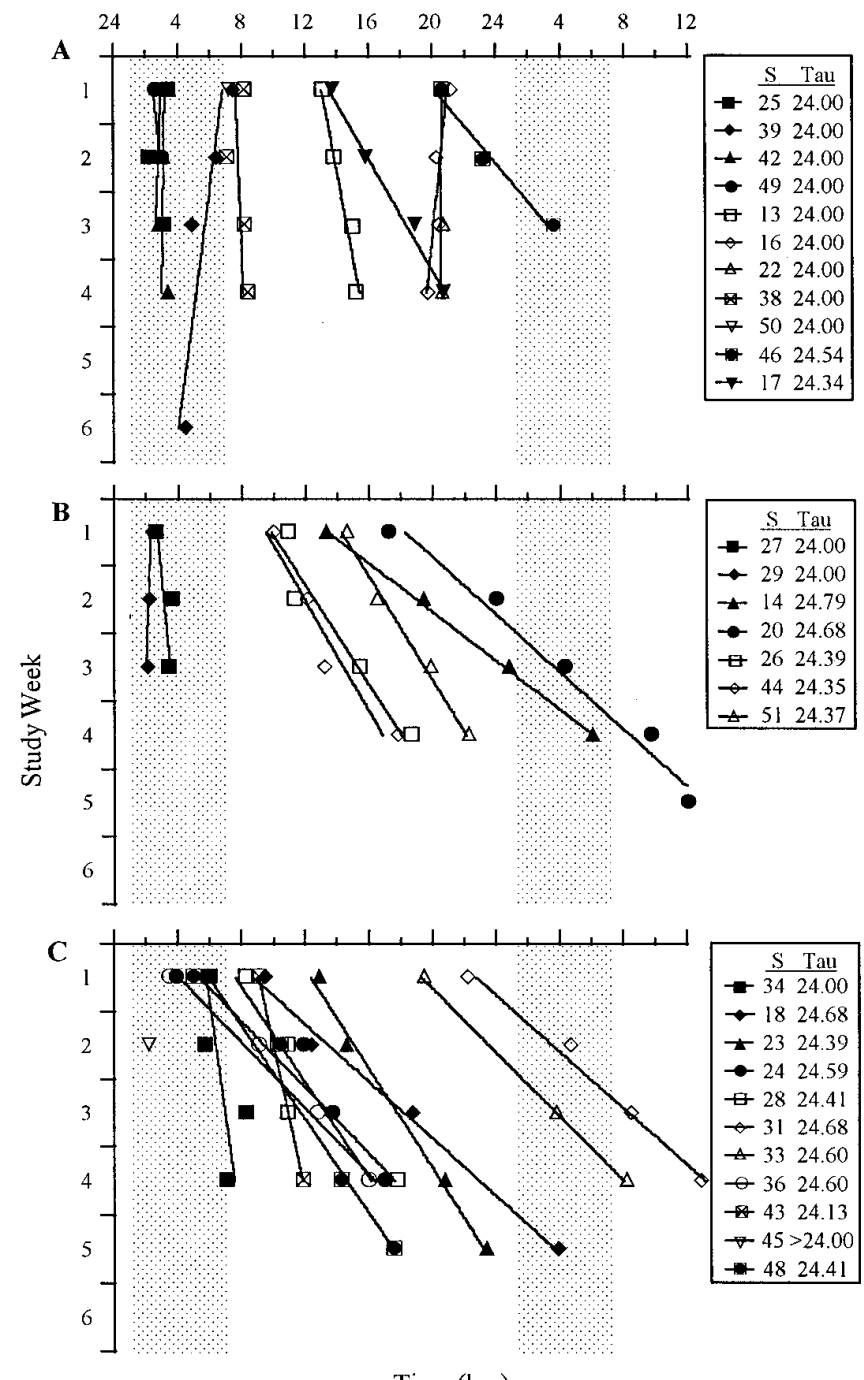

Time (hrs)

FIG. 3. A-C, Individual weekly aMT6s acrophase with the associated regression lines for each NPL subject according to the number of eyes present (two eyes, one eyes, or no eye present, respectively). The shaded area represents the range of aMT6s acrophases for normally entrained individuals $(\mathrm{n}=80$ ) (English J. and Arendt J., unpublished results). The key shows the subject number (S) and the associated $\tau$ (hours) of the aMT6s rhythms.

rhythm, and that we studied S34 during a normal phase of a very slow, free running cycle. Alternatively, nonphotic zeitgebers may be entraining the rhythm: the existence of such individuals has been previously reported (32).

In those NPL subjects with entrained aMT6s rhythms, this study cannot determine whether the entrainment is via subconscious light perception or by nonphotic zeitgebers. An evaluation of melatonin suppression by light $(32,35)$ would indirectly test the integrity of retina-RHT-SCN function in NPL subjects. The identification and role of nonphotic time cues in human circadian rhythms still requires thorough investigation. Most of the free running blind subjects (14 of 17) were fully employed with conventional working hours. As their aMT6s rhythms were not entrained by the very strong temporal and social signals associated with keeping working hours, our results imply that the influence of non- photic zeitgebers on aMT6s rhythms in blind individuals is likely to be highly individual.

This study used urinary aMT6s as a marker of circadian rhythmicity. There is extensive evidence that urinary aMT6s faithfully reflects the timing of both the plasma aMT6s and melatonin rhythm in entrained and phase-shifted conditions (5-11). Although the resolution of such rhythm assessments could be improved by sampling plasma at frequent intervals, this method, however, is impractical for long term field studies. The amount of melatonin produced over $24 \mathrm{~h}$ does not appear to differ in blind subjects compared to sighted individuals (18). Our results confirm the well documented decreases in overall melatonin production and amplitude associated with increasing age (17-19). No other variables were associated with changes in total aMT6s production.

There are both LP and NPL subjects who appear to be abnormally entrained to a 24-h day, a result also described in previous studies $(25,31)$. These results may be artifactual due to the restricted length of the study period. A rhythm appearing abnormally entrained may be free running, but with a period very close to $24 \mathrm{~h}$, and would, therefore, take many weeks to exhibit a clear free running rhythm. Similarly, repeated measurements at regular intervals may coincidentally measure the rhythm at the same circadian period. To control for this, longitudinal studies are required that measure rhythms at irregular intervals over at least several months, and these are currently being completed.

The abnormal timing of strongly endogenous circadian rhythms (e.g. melatonin, core body temperature, and cortisol) is known to be associated with some sleep disorders (28-34). In the present study, the PSQI was used to select patients with disordered sleep and therefore possibly disordered circadian rhythms. Our results show that individuals with free running rhythms had a higher PSQI score than normally entrained individuals. This difference did not reach statistical significance because there was a small proportion of individuals $(\mathrm{n}=3)$ with free running rhythms who did not report a subjective sleep disorder according to the PSQI (PSQI score, <5).

The effects of specific visual diseases on light processing for circadian function in humans is unknown. Studies have attempted to isolate the retinal photoreceptors required for circadian entrainment $(43,44)$, but it is still unclear whether rods, cones, a novel photoreceptor, or a combination or subset of photoreceptor types are involved. Although the association between human ocular disease type and circadian rhythms has not been investigated fully, preliminary studies of color-blind individuals suggest that deficient cone function has no effect on the ability of melatonin to be suppressed by light (45). Due to the large diversity of visual disorders in the study population, this report can only draw preliminary conclusions about the relationship between disease type and circadian rhythms in the blind. Several diseases were relatively common and could be associated with circadian rhythm status. Fourteen subjects were diagnosed as having $\mathrm{RP}$, a group of disorders, some of which affect rods primarily and others of which affect midperipheral rods and cones. The majority of these $(\mathrm{n}=11 ; 79 \%)$ had normally entrained rhythms, suggesting that RP does not significantly interfere with photic information processing for circadian entrain- 
ment. The possibility exists, however, that a mutation different from those in the subjects tested might affect circadian entrainment. Of the seven individuals with retinal detachments, two were normally entrained, four appeared to have abnormally entrained aMT6s rhythms, and one was free running. Interestingly, of only five NPL individuals in total with abnormally entrained rhythms, four of these $(80 \%)$ had retinal detachments. These preliminary observations should prompt a closer inspection of visual disease in addition to levels of light perception of individuals when investigating circadian rhythms in blind subjects.

In conclusion, this study has shown that blind individuals with no perception of light (NPL) have a higher incidence of circadian rhythm disorders than subjects with light perception, as measured by aMT6s production.

\section{References}

1. Arendt J. 1995 Melatonin and the mammalian pineal gland. London: Chapman and Hall.

2. Akerstedt T, Froberg JE, Friberg Y, Wetterberg L. 1979 Melatonin excretion, body temperature and subjective arousal during 64 hours of sleep deprivation. Psychoneuroendocrinology. 4:219-225.

3. Vaughan GM, McDonald SD, Jordan RM, et al. 1978 Melatonin concentration in human blood and cerebrospinal fluid: relationship to stress. J Clin Endocrinol Metab. 47:220-223.

4. Wever RA. 1989 Light effects on human circadian rhythms: a review of recent Andechs experiments. J Biol Rhythms. 4:161-185.

5. Arendt J, Bojkowski C, Franey C, Wright J, Marks V. 1985 Immunoassay of 6-hydroxymelatonin sulfate in human plasma and urine: abolition of the urinary 24-hour rhythm with atenolol. J Clin Endocrinol Metab. 60:1166-1173.

6. Markey SP, Higa S, Shih M, Danforth DN, Tamarkin L. 1985 The correlation between human plasma melatonin levels and urinary 6-hydroxymelatonin excretion. Clin Chim Acta. 150:221-225.

7. Bojkowski CJ, Aldhous ME, English J, et al. 1987 Suppression of nocturnal plasma melatonin and 6-sulphatoxymelatonin by bright and dim light in man. Horm Metab Res. 19:437-440.

8. Bojkowski CJ, Arendt J, Shih MC, Markey SP. 1987 Melatonin secretion in humans assessed by measuring its metabolite, 6-sulphatoxymelatonin. Clin Chem. 33:1343-1348.

9. Bojkowski C, Arendt J. 1988 Annual changes in 6-sulphatoxymelatonin excretion in man. Acta Endocrinol (Copenh). 117:470-476.

10. Deacon S, Arendt J. 1994 Phase-shifts in melatonin, 6-sulphatoxymelatonin and alertness rhythms after treatment with moderately bright light at night. Clin Endocrinol (Oxf). 40:413-420.

11. Ross JK, Arendt J, Horne J, Haston W. 1995 Night-shift work in Antarctica: sleep characteristics and bright light treatment. Physiol Behav. 57:1169-1174.

12. Waldhauser F, Vierhapper H, Pirich K. 1986 Abnormal circadian melatonin secretion in night-shift workers. N Engl J Med. 18:1614.

13. Sack RL, Blood ML, Lewy AJ. 1992 Melatonin rhythms in night shift workers. Sleep. 15:434-441.

14. Fevre-Montange $M$, Van Cauter $E$, Refetoff $S$, Desir D, Tourniaire Copinschi G. 1981 Effects of "jet lag" on hormonal patterns. II. Adaptations of melatonin circadian periodicity. J Clin Endocrinol Metab. 52:642-649.

15. Arendt J, Aldhous M, English J, Marks V, Arendt JH. 1987 Some effects of jet lag and their alleviation by melatonin. Ergonomics. 30:1379-1393.

16. Harma M, Laitinen J, Partinen M, Suvanto S. 1993 The effect of four-day round trip flights over 10 time zones on the circadian variation of salivary melatonin and cortisol in airline flight attendants. Ergonomics. 37:1479-1489.

17. Iguchi H, Kato K-I, Ibayashi H. 1982 Age-dependent reduction in serum melatonin concentrations in healthy human subjects. J Clin Endocrinol Metab. 55:27-29

18. Bojkowski C, Arendt J. 1990 Factors influencing urinary 6-sulphatoxymelatonin, a major melatonin metabolite, in normal human subjects. Clin Endocrinol (Oxf). 33:435-444.
19. Haimov I, Laudon M, Zisapel N, et al. 1994 Sleep disorders and melatonin rhythms in elderly people. Br Med J. 309:167.

20. Arendt J, Bojkowski C, Folkard S, et al. 1985 Some effects of melatonin and the control of its secretion in humans. In: Evered DC, Clark S, eds. Photoperiodism, melatonin and the pineal (Ciba Foundation Symposium), 117th ed London: Pittman; 266-283.

21. Johnson RF, Moore RY, Morin LP. 1988 Loss of entrainment and anatomical plasticity after lesions of the hamster retinohypothalamic tract. Brain Res. 460:297-313.

22. Smith JA, O'Hara J, Schiff AA. 1981 Altered diurnal serum melatonin rhythm in blind men. Lancet. ii:933.

23. Miles LEM, Raynal DM, Wilson MA. 1977 Blind man living in normal society has circadian rhythms of 24.9 hours. Science. 198:421-423.

24. Orth DN, Besser GM, King PH, Nicholson WE. 1979 Free-running circadian plasma cortisol rhythm in a blind human subject. Clin Endocrinol (Oxf) 10:603-617.

25. Lewy AJ, Newsome DA. 1983 Different types of melatonin circadian secretory rhythms in some blind subjects. J Clin Endocrinol Metab. 56:1103-1107.

26. Okawa M, Nanami T, Wada S, et al. 1987 Four congenitally blind children with circadian sleep-wake rhythm disorder. Sleep. 10:101-110.

27. Arendt J, Aldhous M, Wright J. 1988 Synchronisation of a disturbed sleepwake cycle in a blind man by melatonin treatment. Lancet. i:772-773.

28. Aldhous ME, Arendt J. 1993 Assessment of melatonin rhythms and the sleepwake cycle in blind subjects. Adv Pineal Res. 5:307-309.

29. Tzischinsky O, Skene DJ, Epstein R, Lavie P. 1991 Circadian rhythms in 6-sulphatoxymelatonin and nocturnal sleep in blind children. Chronobiol Int. 8:168-175.

30. Nakagawa H, Sack RL, Lewy AJ. 1992 Sleep propensity free-runs with the temperature, melatonin and cortisol rhythms in a totally blind person. Sleep. 15:330-336

31. Sack RL, Lewy AJ, Blood ML, Keith LD, Nakagawa H. 1992 Circadian rhythm abnormalities in totally blind people: incidence and clinical significance. J Clin Endocrinol Metab. 75:127-134.

32. Czeisler CA, Shanahan TL, Klerman EB, et al. 1995 Suppression of melatonin secretion in some blind patients by exposure to bright light. N Engl J Med. 332:6-11

33. Lockley S, Tabandeh H, Skene D, et al. 1995 Day-time naps and melatonin in blind people. Lancet. 346:1491.

34. Lockley SW, Skene DJ, Tabandeh H, Bird AC, Defrance R, Arendt J. 1997 Relationship between napping and melatonin in the blind. J Biol Rhythms. 12:16-25

35. Lewy AJ, Wehr TA, Goodwin FK. 1980 Light suppresses melatonin secretion in humans. Science. 210:1267-1269.

36. Brainard GC, Lewy AJ, Menaker M, et al. 1988 Dose-response relationship between light irradiance and the suppression of plasma melatonin in human volunteers. Brain Res. 454:212-218.

37. McIntyre IM, Norman TR, Borrows GD, Armstrong SM. 1989 Human melatonin response to light at different times of the night. Psychoneuroendocrinology. 14:187-193.

38. Broadway J, Arendt J, Folkard S. 1987 Bright light phase shifts the human melatonin rhythm during the Antarctic winter. Neurosci Lett. 79:185-189.

39. Boivin DB, Duffy JF, Kronauer RE, Czeisler CA. 1996 Dose-response relationships for resetting of human circadian clock by light. Nature. 379:540-542

40. Tabandeh H, Lockley S, Skene D, Bird AC, Arendt J, Defrance R. 1995 Disturbances of sleep in blindness. Invest Ophthalmol Vis Sci. 34:S808.

41. Buysse DJ, Reynolds III CF, Monk TH, Berman SR, Kupfer DJ. 1989 The Pittsburgh Sleep Quality Index: a new instrument for psychiatric practice and research. Psychiatry Res. 28:193-213.

42. Aldhous M, Arendt J. 1988 Radioimmunoassay for 6-sulphatoxymelatonin in urine using an iodinated tracer. Ann Clin Biochem. 25:298-303.

43. Foster RG, Argamaso S, Coleman S, Colwell CS, Lederman A, Provencio I. 1993 Photoreceptors regulating circadian behaviour: a mouse model. J Biol Rhythms. 8:S17-S23.

44. Provencio I, Wong S, Lederman AB, Argamaso SM, Foster RG. 1994 Visual and circadian responses to light in aged retinally degenerate mice. Vision Res. 34:1799-1806.

45. Ruberg FL, Skene DJ, Hanifin JP, et al. 1996 Melatonin regulation in humans with colour vision deficiencies. J Clin Endocrinol Metab. 81:2980-2985. 